\title{
LA ENSEÑANZA DE LA MEDICINA EN LA ERA DE LA GLOBALIZACIÓN
}

\section{Medical education in times of globalization}

Seguramente todos quienes llevamos ya más que algunos años ejerciendo la Medicina, al evocar nuestro período de formación de pre y posgrado, recordamos con cariño a alguno de nuestros maestros. Y los recordamos no tanto por lo mucho que sabían, sino sobre todo por el tiempo que nos dedicaban, su vocación docente y las virtudes humanas que poseían. Se constituían asi en nuestros modelos y por mucho tiempo, cuando nos tocaba enfrentar un problema médico, nos preguntábamos: ¿Cómo resolvería este caso mi maestro? La enseñanza de la medicina se hacía en ese entonces, por modelaje, de acuerdo a la tradición y en forma bastante intuitiva.

Desde hace algunas décadas, la educación médica se ha ido profesionalizando cada vez más convirtiéndose en una verdadera especialidad. Casi todas las Facultades y Escuelas de Medicina tienen hoy unidades de Educación Médica que velan por la calidad de ésta, a través de la revisión permanente de los currículos $y$ de la formación y perfeccionamiento de sus académicos.

La enseñanza centrada en el profesor, está siendo reemplazada por nuevas formas de docencia centradas en el estudiante. El objetivo es el aprendizaje y el docente hace de facilitador de éste. El estudiante abandona su rol pasivo y se constituye en verdadero artifice de su propio saber. Para ello el profesor debe estar entrenado en las nuevas y diversas metodologías de la enseñanza, como el aprendizaje basado en problemas o en casos clínicos, la técnica del rol playing, la filmación de entrevistas reales o simuladas y la utilización de simuladores de distinto tipo.

Los currículos basados en resultados de aprendizaje y no en contenidos fragmentados, nos han obligado a replantear nuestros programas de formación. La explosión del conocimiento y su accesibilidad inmediata, nos hace ver la responsabilidad de las Facultades de Medicina en formar a nuestros médicos con sólidos conocimientos en su quehacer profesional pero sobre todo enseñarles a aprender y a autoevaluarse permanentemente. En este sentido el rol de las evaluaciones objetivas, con múltiples instrumentos y principalmente formativas, que dirijan el aprendizaje y fomenten la reflexión sobre el propio desempeño es crucial para asegurar que nuestro producto de salida sea realmente competente.

Hoy nuestras instituciones tienen el desafio de abordar una preparación integral del médico desde el pregrado, abarcando el postgrado y la formación continua durante toda su vida profesional.

El año 2011 la OMS define el consenso global sobre responsabilidad social de las Facultades de Medicina: "hacer bien lo que se debe hacer y rendir cuenta de cómo, por qué y para qué se hace", como función ineludible.

A esto se ha llegado en gran medida por la globalización, que ha incidido fuertemente en la medicina y su enseñanza, la que a través de distintas sociedades y asociaciones como la Federación Mundial de Educación Médica (WFME) busca la construcción de estándares internacionales para la educación.

Con algunas variantes propias de cada país y cultura, se pretende que todos los médicos del mundo tengan una formación igualitaria que les permita el día de mañana trabajar en cualquier lugar donde se les necesite.

La educación médica en Chile, adoptando estas tendencias, desarrolla diversas estrategias que van en la línea de una enseñanza médica estandarizada: el EUNACOM (Examen Único Nacional de Conocimientos en Medicina) y el Perfil común de competencias consensuado por las Facultades de Medicina de ASOFA$M E C H$, pretenden ser una guía para orientar los currículos y asegurar que todos los estudiantes del país y los extranjeros que ejercen la medicina en Chile los cumplan. 
La Ley de Aseguramiento de la Calidad de la Educación Superior, obliga a acreditar las carreras de medicina, para lo cual deben lograr determinados estándares.

La Ley de Derechos y Deberes del paciente pone condiciones al acceso a la ficha clínica de éste y también a su examen. Si a esto se suma la escasez de campos clínicos, la enseñanza a la cabecera del paciente se dificulta y cobra especial interés el aprendizaje en base a la simulación, como una etapa previa al enfrentamiento con el enfermo. Pero además, esta metodología de enseñanza va en beneficio de la seguridad del mismo, ya que permite que el estudiante y también el médico practiquen técnicas de examen o procedimientos en un ambiente seguro, en que puedan cometer errores y corregirlos, para llegar luego a ponerlos en práctica con seguridad.

La educación a distancia es otra herramienta propia de esta era de la globalización, permitiendo por ejemplo videoconferencias o seminarios con profesores que están a veces a miles de kilómetros de distancia, o realizar cursos a través del sistema de e-learning en prestigiosas Universidades nacionales y extranjeras.

En resumen, estamos viviendo una enseñanza de la medicina globalizada, estandarizada y evaluada, tanto por parte del docente como del estudiante, que es hoy el centro del proceso.

Alguien podría preguntarse, ¿es esta enseñanza mejor que la de antaño? Me parece que la respuesta es: cada metodología con su tiempo. Asumiendo hoy, la formación de un médico que tiene nuevos roles: comunicador, gestor del conocimiento y de los recursos sanitarios, experto, profesional, gerente-directivo y agente principal del sistema.

Sin embargo, los elementos básicos de una buena enseñanza siguen siendo los mismos: docentes con vocación y tiempo para dedicarle a sus estudiantes, estudiantes interesados por aprender y los medios necesarios para hacer posible el proceso.

Prof. Dr. Rogelio Altuzarra H.

Decano

Facultad de Medicina

Universidad de los Andes

Santiago, Chile.

raltuzarra@uandes.cl 